\title{
Analysis of Self-protecting Equipment (APD) Effectiveness for Ship Crews at Work on Board
}

Received: 20 July 2019

Accepted: 22 August 2019

Published: 29 August 2019

Publishing services provided by Knowledge E

(c) . This article is distributed under the terms of the

Commons Attribution License, which permits unrestricted use and redistribution provided that the original author and source are credited.

Selection and Peer-review under the responsibility of the ICTSD 2018 Conference Committee.
G OPEN ACCESS

\section{Abstract}

Ships have proven to be effective mode for $80 \%$ of global commodity trade transported by sea. Working at ships poses a high risk. According to Heinrich, $88 \%$ of accidents at work can be prevented. It means that improving behaviors of the sailors can prevent the accidents up to $88 \%$. This research was done on the sailors to find out their behaviors in applying the self-protecting equipment (APD) to prevent the accidents. The research population consisted of $1501^{\text {st }}$ to $4^{\text {th }}$ grade student-officers attending nautical and engineering departments. The research used is a quantitative methodology with questioner dissemination. The result shows that knowledge and understanding about APD and the risk of not using the APD were high. However, the percentage of the APD application and maintenance were still low. Therefore, the effectiveness of its use was not optimal. The research recommended a good APD maintenance by the ship management on a regular basis and scrutiny towards the APD availability on the ship.

Keywords: safety at work, sailors, self-protecting equipment

\section{Introduction}

Sea transport has been responsible for the delivery of more than $60 \%$ of total high economic value commodities in global trade (Janson, 2005). Ship as the sea transportation mode has proven to be very effective. Therefore, job opportunities in this sector are still widely open. Working at the sea poses a high risk of safety and security because natural/weather factors dominate during the work. The natural threats produce particular risk in addition to the general risks at work. Furthermore, workers are also faced by psychological and boredom factors. Equally important, the sailors' behaviors at work are the key to the successful work at the sea. Therefore, their knowledge and understanding about life safety is very important in order to prevent themselves from potential accidents.

Accidents do not always happen beyond one's expectation. They can also take place due to his or her careless behaviors or attitudes. It is everyone's duty to prevent such 
under controlled factors as human, environment, and equipment from being put the workers in danger. Yet, human factor becomes the most prevalent factor causing the accidents.

The accidents at work can be prevented. Heinrich believes that $88 \%$ of the accidents can be prevented, whereas according to Dupont even $96 \%$ of the accidents are preventable. The findings hypothesize that workers' behaviors are effective to prevent $88 \%$ to $96 \%$ of the accidents at work. This research was performed because the accidents at work still occur due to human factors. These factors can be found in terms of the use, application, and maintenance of the self-protecting equipment (APD).

According to the Indonesia's Social Security Provision Board (BPJS) on Employment Affairs, the accidents at work in this country continue to rise as one can figure out the more claims endorsed. The accidents at work in 2017 hit 123,000 cases on the claim value of 971 billion rupiahs. Such figure was higher than the previous year, 2016, in which the accidents claimed as much as 792 billion rupiahs.

APD is a series of mandatory equipment that must be prepared prior to the work because of their functions of protecting body parts. Each function from head to toe is particular and indispensable during the work. Each company, including the shipping and maritime enterprises, is required to provide the APD and to socialize it to the workers concerning the use and application towards safety at work.

The requirement of wearing the APD has been a mutual agreement between the business and the government, i.e. the Ministry of Employment and Transmigration, under the Decree of the Minister of Employment and Transmigration No.Per.08/Men/VII/2010 on self-protection. Each company is required to provide the APD to the workers and employees to support the work system and safety and health at work.

Many fatal accidents occurred due to ignorance to the APD. Compared to other countries, the accidents at work in Indonesia have occurred more often because of poor knowledge about using the APD. Therefore, extension and education, followed by training, must be provided to the workers or employees concerning the APD and its use.

Furthermore, the company is also required to implement Safety and Health at Work Management System (SMK3) to improve the knowledge of the workers of the importance of the safety and health at the work place. Not any single accident can be tolerated as far as it is due to human factor because it can result in fatality. The SMK3 implementation, therefore, must also be strengthened by scrutiny and supervision towards the workers, i.e. they must be voluntarily willing to wear the APD when doing their duties. The APD use and maintenance on a regular basis must also be put into priority by the employers 
for optimal use of the equipment, becoming the key to success of the company since the work environment becomes secured and convenient.

\subsection{Self-Protecting Equipment (APD)}

APD comprises the protecting equipment that attach to the human body from head to toe, i.e. helmet, goggles, mask, ear plug/ear muff, gloves, wear pack, and boots. The workers need more specific APD when working at specific environment, such as chemical tanker, which transport harmful substances, unlike those working at the container vessels.

\section{APD Categorization}

1. Head protectors: Helmet, Safety Glass (goggles), Masker, Respirator, Ear Plugs/ Ear Muff.

\section{a. Safety Helmet}

Helmet is worn as head protector from being exposed by any harm, such as being hit by tools or contacted by electricity. The safety helmet application must be based on convenience and efficiency requirements of the user.

Helmet types for preventing from electricity-related accidents are as follows:

1. General (G) Type Helmet. It protects the head from being hit and contacted by devices with low electricity load (200 V).

2. 200 Volt Electrical (E) Type Helmet. It protects the head from being hit or contact by devices with high electricity load (2200 V).

3. Conductive (C) Type Helmet. It protects the head from being hit or contacted by non-electrical devices.

\section{b. Safety Glasses}

Safety glasses protect the workers' eyes from being hit by sharp tools, dust, and tiny particulates, even light and chemical splash. There are two kinds of safety glasses, i.e.:

1. Safety Spectacles, protecting the eyes from being hit by sharp tools, dust, tiny particulates, and being exposed by high beam. 
2. Safety Goggles, protecting the eyes from being exposed by chemical splash, smoke, steam, dust, and sharp tools.

\section{c. Ear Plug}

Ear plug is used for protecting the hearing organs from high intensity sounds. This equipment can reduce the intensity up to $10-15 \mathrm{~dB}$ and is generally used by the workers at machinery chambers.

\section{d. Ear Muff}

Similarly, ear muff also protects the human's ears from being exposed by high intensity sounds. However, its capability of intensity reduction is 20-30 dB. This equipment is divided into head band and ear cup made of Styrofoam to protect the outer part of the ears. Engineers at the machinery and generator chambers are familiar with such device.

\section{e. Mask}

Mask is a device that protects the respiratory organs, i.e. nose and mouth, from being exposed by harmful smoke, dust, and bad smell from chemical substances. This device is made of either linen or paper.

f. Respirator Respirator protects respiratory organs, i.e. nose and mouth, from potential exposition of smoke, chemical substances, dust, steam, gas, mist particles, and fume particles. This device is often used by machine engineers, painting operators, and those working at the chemical manufacture.

\section{Body Protector: Apron}

Apron protects the body from being exposed by chemicals and heat.

\section{Body Protectors: Safety Shoes/Boot, Hand Gloves}

a. Hand protectors are used for protecting the hands from being chemically exposed, torn, and injured by sharp tools. Hand gloves are generally used the chemical preparation system, sharp component installation, and heating process. The following are several types of gloves:

1). Cotton Gloves, used for protecting the hands from being torn, sliced, and minor injury.

2). Leather Gloves, used for protecting the hands from being tore, sliced, and received minor injury.

3). Rubber Gloves, used for protecting the hands from being exposed by chemicals, e.g. lubricant, oil, glue, and grease. 
4). Electrical Gloves, used for protecting the hands during the contact with high or low electricity.

\section{b. Safety Shoes/Boot}

Safety boots protect the feet from being hit by tools, in particular the sharp ones, spoiled by chemicals, and contacted by electricity. The boots are equipped with steel tip and rubber wrap.

\section{Research Methodology}

This research applied a quantitative research methodology with questioner dissemination under the Likert theory and in-depth interview methods. The respondents of the research were sailors (student-officers) from $1^{\text {st }}$ to $4^{\text {th }}$ grade of the nautical (75 students) and engineering departments (75 students).

\section{Discussion}

The observation was done with 150 student-officers, resulting in the followings: $90 \%$ respondents with understanding about APD on board; 94\% respondents with understanding about the APD demonstration; 91\% ship crews performing the APD demonstration; $90 \%$ ship crews explaining the function and use of APD; and 91\% ship crews with complete APD. Of the 150 sailors, $89 \%$ wore the APD properly; $95.7 \%$ ship crews had knowledge of operating the APD; 95\% ship crews knew the function of the APD; 93\% ship crews knew the risk of not using the APD; $89 \%$ senior officers took part into the APD supervision; and $89 \%$ senior officers did regular checking of the APD on board.

Furthermore, $90 \%$ of the ship crews understood the function of the APD on board, either at the deck (90\%) or the engine chamber (91\%). The observation also found $91 \%$ of the ship management provided the APD for daily activity and $90 \%$ having the reserve APD at the store. Finally, $89 \%$ of the $1{ }^{\text {st }}$ Class officers responsible for the safety on board did the APD maintenance.

\section{Conclusion}

The knowledge of the student-officers about the APD had been relatively high but some ship crews remained low in understanding the proper function and operation of such equipment due to the absence of the supervision and scrutiny by the senior officers. 
There were still some crews unwilling to apply the APD during the work because of inconvenient or even unsafe feeling. The maintenance by the ship management is mandatory to provide better equipment for the safety at work on board. The mutual understanding and awareness among the crews will be necessarily important towards the safer and healthier environment during the operation on the ship. 